\title{
Facilitating communication about books through an online community
}

\author{
Connie Golsteijn • Elise van den Hoven
}

Received: 28 February 2010/Accepted: 21 May 2010/Published online: 17 June 2010

(C) The Author(s) 2010. This article is published with open access at Springerlink.com

\begin{abstract}
Reading books can serve as a means of gathering information, relaxing and escaping daily stress. Although reading is often primarily an individual activity, many readers also enjoy sharing reading experiences with friends, relatives, colleagues and, through the internet, even with strangers. Apart from valuing these individual and collective book activities, books as physical artifacts are also valued, for example because of the memories associated with them. This paper investigates how books can be enhanced with a new product, system or service. In a qualitative interview study, the main reasons for valuing books were found to be related to the self (individual activities and feelings), experiences (e.g., enjoyment or release) and personal values (e.g., embodiment of ideals or personification). As a result, it was decided for the remainder of this study to focus on communication about books, because in addition to individual book-related activities and feelings, users indicated to communicate about books a lot. A book community Web site, called Shelf, was developed to investigate whether book communication could be increased by facilitating an online community and whether users would appreciate the Web site functionality. Shelf was used in a 14-day user evaluation, and it was concluded that the Web site increased the extent to which readers communicated about books. We expect that such an online book community would be a
\end{abstract}

C. Golsteijn $(\varangle) \cdot$ E. van den Hoven

Industrial Design Department, Eindhoven University

of Technology, P.O. Box 513, 5600 MB Eindhoven,

The Netherlands

e-mail: info@conniegolsteijn.com

E. van den Hoven

e-mail: e.v.d.hoven@tue.nl valuable enhancement of current book customs, in particular in combination with the current e-book trend, for various types of readers who would like to share their experiences.

Keywords Keepsake objects - Books ·

Online community · Internet communication ·

Design research $\cdot$ Interaction design

\section{Introduction}

Nowadays new products are being designed daily and homes are filled with new, innovative objects and systems. The objects that are most valuable to people, however, are often not the most intelligent, advanced, or beautiful ones. The most valued objects, the so-called keepsakes objects: objects which hold personal significance to an individual [1, p. 90], are a subset of what psychology refers to as cherished possessions: objects belonging to an individual which are considered special [2; as mentioned in 1, p. 90]. Cherished possessions can be anything, e.g., electronic equipment, cars, pets. Keepsake objects, on the other hand, are objects that are kept over time, and their value is rooted in their personal history. If a keepsake object is lost, it cannot be replaced. Almost any object can become a keepsake object, although certain objects have a greater tendency to become one, e.g., heirlooms and souvenirs [1]. So when new products are being brought into people's homes, it will take some time before they can become keepsakes. The question arises whether new products would become more valuable if we would enhance existing artifacts. A study was done investigating for a specific type of valued artifacts, namely books, how these artifacts can be enhanced with a new product, system or service. This 
resulted in the design and evaluation of a community Web site facilitating book discussions, called Shelf.

In the remainder of this paper, we will use the term artifact to indicate a physical object. We will provide an overview of related work done in the field of valued artifacts, book customs, communication networks and augmented books (Sect. 2), after which we will explain why people value books based on an interview study (Sect. 3). Subsequently, the idea generation, concept development (Sect. 4) and implementation of Shelf (Sect. 5) will be addressed. Shelf was evaluated in a 14-day user study, which will be addressed in Sects. 6 and 7, followed by a discussion (Sect. 8) and conclusions (Sect. 9).

\section{Related work}

The goal of our study focused on enhancing artifacts that are special to their owners, such as keepsakes. Physical artifacts can play various roles in people's lives, e.g., they embody memories or are used in home altars to reminisce the deceased (called autotopography) [3]. People surround themselves by artifacts that are physical embodiments of aspects of the self and that help in the establishment, expression and maintenance of self-identity [1]. These artifacts serve as a memory landscape to the owner and physically shape an autobiography because they link to memories that are important to the owner. Since those memories are important to the owner, the artifacts that link to them are also important [4]. Petrelli et al. [5] conducted a field study to understand the principles underlying the relations between people, their memories and their artifacts. This study has shown that people relate to a small number of carefully selected artifacts (mementos) that are meaningful. These mementos can have different functions, e.g., supporting social display and conversation when placed in public places, or unlocking emotions when placed in private places. When designing technology for such personal mementos and related memories, these functions need to be considered to avoid creating devices that do not reflect these processes [5].

When taking an artifact, such as a memento or keepsake object, as a starting point, how can one make an appreciated enhancement? Glos and Cassell [1] state that in order to digitally augment a personal artifact, one first has to look at the characteristics that make it powerful as a keepsake and then focus on strengthening exactly these characteristics. Understanding why a keepsake is considered special appears to be the first step towards an enhanced keepsake. Clearly, the reasons for cherishing are different for each individual artifact. Therefore, we decided to focus on one specific type of keepsakes people have in their homes, namely books.
The reason for selecting books came from a large-scale interview study by Csikszentmihalyi and Rochberg-Halton [6] who investigated the artifacts in people's homes that were cherished most, including keepsakes. The five artifact categories that were found to be cherished most were 1-furniture, 2-visual art, 3-photographs, 4-books, and 5-stereos. We chose to study books, because of our own personal interests and since this was a largely unexplored area.

\subsection{Book customs}

Nowadays information is available everywhere, and many things that used to be available only in books can be found on the internet. And yet physical bookstores as well as online book stores, like amazon.com, are flourishing. Apparently, even in this digital age, people still attach value to books. In this study, a book was defined as: a set of printed sheets bound together into a volume [7] of which more than one copy exists, that can, or could, be acquired in its original state. The latter part of the definition was added to exclude one of a kind and self-created books, like photo albums and diaries, which were outside the scope of this study. The definition does include self-written books like dissertations, as long as they were published or printed. It also includes books which contain written notes or adjustments, as long as they were originally available in more than one copy. The target group for this study was adults, because it was assumed adults value books more than children or teenagers and that they have built up larger collections of books they may value. These definitions of a book and a target group are a starting point for an investigation of book customs in the Netherlands, where this study was done.

In 2006, consumers in the Netherlands have spent over 1.6 billion Euros on books. Bookstores had the largest market share with $55 \%$ of all sales. Another $33 \%$ was sold through non-retail businesses, such as scholarships, libraries and news papers. The remaining $13 \%$ was sold through supermarkets, department stores, ambulant businesses, mail-order and internet companies. While the number of bookstores decreased and bookstores have had two difficult years, book sales have been rising again since 2005. The average amount of money spent on books per household increased as well over the last 5 years [8].

On the contrary, libraries in the Netherlands are struggling. The number of libraries in the Netherlands has decreased and fewer people have subscribed to libraries. Also, fewer adults have subscriptions, and the adults with subscriptions borrow fewer books. Non-fiction books especially were borrowed less. In 2005, adults borrowed an average of 33 books, and of all borrowed items $90 \%$ were books. Since 2006, there has been a small rise in the number of borrowed books, especially because more juvenile books were borrowed [8]. It seems that although 
more books are sold, the interest in borrowing them has decreased.

While more books are sold, the Dutch spend less time reading printed media. In 1975, $6 \mathrm{~h}$ were spent per week reading printed media, like books, magazines and news papers. In 1990, this time reduced to $5 \mathrm{~h}$, and in 2005 even less than $4 \mathrm{~h}$ were spent reading. This decrease is higher for magazines and news papers than for books. Increasingly more time is spent on internet and watching TV: an average of more than $15 \mathrm{~h}$ per week was spent on these media in 2005 [8]. However, it is not clear how much time on the internet is spent on reading. Although less time is spent reading printed media and more time is spent online, book sales are rising again, which supports our initial assumption that people still attach value to books. Although books are often used in individual activities, many readers also enjoy sharing their reading experiences, through face-to-face and online book communication. The next section will address related work in the area of book communication.

\subsection{Book communication}

Communication about books is done face-to-face or online, the two most common approaches. For face-to-face book communication, we will use Daniels' [9, p. 2] definition of literature circles: small, peer-led discussion groups whose members have chosen to read the same story, poem, article or book. In this definition, we include all face-to-face book discussions, e.g., literature circles used in education, book clubs or adult reading groups. Adult reading groups are voluntary groups of friends who meet periodically in one another's living rooms, in church basements, in the back rooms of bookstores, etc., and read books that move them or change them as people and that create a powerful and caring community among them [9, p. 3]. With online book communication, we mean any form of communication through a threaded discussion: a discussion in which a group of individuals is connected through an electronic medium, such as an e-mail distribution list, online conference group, newsgroup, forum, or internet-based bulletin board service [10, p. 3].

Despite the well-known existence of contemporary book clubs, whose members meet both in face-to-face and in online book discussions, according to Sedo [11] surprisingly few academic studies have been done about both face-to-face and online book communication. Both categories will be outlined below.

\subsubsection{Face-to-face book communication}

Typically in organized face-to-face book communication, such as literature circles, members make notes while reading to help them contribute to periodic discussions on the chosen books. In education all over the world, literature circles have been used to increase students' understanding in literature and encourage their love of reading. According to Daniels [12], literature circles are successful in education due to an increased engagement, choice and responsibility for students. Diverse tools have been used to support educational literature circles [9, 12], such as post-it notes, to emphasize and remember pieces of text to discuss, role sheets, which outline specific cognitive tasks for each student to take on during discussion, thereby providing a support framework for the discussion, and written communication, in which students simultaneously write notes to each other responding to the literature to increase engagement of all participants.

Apart from education, adult reading groups or book clubs are also a known form of literature circles. As described earlier, these adult reading groups are groups of friends who meet voluntarily to periodically discuss books that interest or move them [9]. Few studies have been conducted on such reading groups. Hartley and Turvey [13] conducted a primarily quantitative study of book clubs in the United Kingdom. Their findings included that book clubs are comprised of primarily women and that learning and exchanging knowledge are the most reported reasons for joining book clubs. Long [14] conducted an extensive ethnographic study of reading groups in the USA in an attempt to analyze women's collective interpretations of texts as a comment on their social lives. She concluded that when books are discussed collectively, readers have the potential to transform in ideas and opinions, individually or as a group, through narratives and characters. Finally, a combination of survey research and in-depth interviews by Howie [15] showed that book clubs provide women with an escape from everyday life and opportunity to change and understand themselves in relation to text and other club members. In addition, book clubs can function as a forum to map developing self-identities. All these studies addressed face-to-face book communication and none extensively explored the impact of the internet on book clubs and online book communication.

To close the gap between face-to-face book communication research and online book communication research, Sedo [11] did an online survey study, studying both faceto-face and online book clubs and shedding light on who readers are, what they read, and that reading is an integral part of people's lives. This research shows that book clubs provide insight in the importance people place on literature and reading and the pleasure they have in both individual and collective interpretation. The most important reason found for using online book communication is that it is a convenient way to connect with other book lovers without geographical or time barriers. Through book club discussions, whether online or face-to-face, members interpret 
books, forming social bonds that allow them to fulfill their desires to learn about the world and themselves [11].

\subsubsection{Online book communication}

The rise of the internet has added various ways of book communication. There are countless Web sites where readers from around the world can participate in online book discussions. Other sites provide step-by-step guides to setting up literature circles and many face-to-face reading groups have their own Web sites to communicate with their members, keep records of their work and share the group's ideas about books and reading groups with a wider audience. Web sites like amazon.com offer information on authors, reviews, sales, related books, and the most recent development, e-books and their accompanying e-readers, which allow readers to access any book anywhere and read it on a light-weight, legible, lap-friendly electronic device [9]. These developments have influenced book discussions, and new communication media have arisen. Although these media are widely used, little research has been done on online book communication. As an exception, a study by Wolsey [10] has shown that in education, online book communication can have great benefits compared to faceto-face literature circles.

In literature circles, students work together to choose and explore literature, which helps them to connect their knowledge to new insights. It promotes active production and not merely the recitation of knowledge [10]. Aside from these advantages, face-to-face book communication can also cause some problems, e.g., students may not be prepared for assigned roles or readings, or students may not be engaged with the discussion process. A solution can be to use online book discussions. A study with eighth-grade students about the effects of threaded book discussions by Wolsey [10] has shown the benefits of such communication: students are allowed time to think about their responses to literature and to comments of others, they do not have to wait their turns and are not interrupted. These and other benefits may also arise from non-educational online book discussions, such as voluntary online book communities, which were aimed at in our study. The online book community in our study was used as an augmentation of books. In the next section, we will address examples of related work on the augmentation of books.

\subsection{Augmented books}

With recent technological developments and increased opportunities to link physical artifacts to digital information, we see a number of interactive book concepts emerging. Many studies have addressed the augmentation of books or other paper-based media, which can be done for various reasons and with various results. Our main goal was to increase communication about books by adding a book community. We found no studies that had a similar goal, although in one case a book was used as a communication medium itself. Davidoff et al. [16] introduces the concept 'BUI': a book as a user interface, in the concept of ElderMail, a system that provides a tangible interface to email for the elderly.

Another way to augment books is changing the interaction with a book, as was done in the Speeder Reader [17]: an interactive reading station that uses the metaphor of driving to go through a story by using a gas pedal and steering wheel. Hengeveld et al. [18] added tangibility to a children's story book by creating a 'BookBooster' that allowed toddlers to go through a cardboard story booklet using a physical slider. Changing the interaction with a book could facilitate more social use of books and book communication, but this was not explicitly addressed in these studies.

Apart from the interaction with a book, the medium itself can be enhanced, e.g., the MagicBook by Billinghurst et al. [19], which expands the physical book with elements of Augmented Realty and Virtual Reality by adding threedimensional virtual images to physical book pages that can be seen through a handheld display. The Augmented Reality story book by Dünser and Hornecker [20] builds on these principles: by interacting with physical book pages and paddles with markers, children can trigger scenes of the story. Scenes are displayed on a screen and transitions from one scene to another are reached through turning the physical pages. Apart from the augmented medium, this last example adds interactivity and flexibility to the story. This was also aimed at by Smith [21], who proposed an interactive comic book that transforms a printed story into an interactive experience through answering questions and touching technologically marked areas of the printed pages. The Listen Reader [22] enhances the reading experience through an interactive audio environment, in which sounds adapt to the different moods and scenes of the story as the reader goes through it. Although these enhanced media, stories and reading experiences can be used by multiple users, they seem to address primarily individual readers' experiences.

Finally, the Meatbook [23] uses a book as a metaphor to provoke visceral reactions from viewers, through an interactive art installation. Such an installation aims at provoking a response, which is quite different from the type of book communication we are interested in supporting, e.g., communication about the story or style of writing.

All in all, although several augmented books, such as the MagicBook [19], the Augmented Reality story book [20], the Listen Reader [22] and the Speeder Reader [17] 
mention a social aspect, none of the discussed studies extensively addresses the social implications of augmented books and possibilities of social networks, which is what this paper seeks to discuss.

\subsubsection{Augmented paper applications}

Apart from augmented books, studies have been done on using technologically augmented paper in practical applications. Chao and Chen [24] have used added line numbers in text on a paper interface to facilitate extracting summaries and questions while reading books via Smartphones, providing access to a virtual learning community. This functionality could be used to support book communication while reading, but since books have to be read digitally, it does not suit our needs for communication about physical books.

Klemmer et al. [25] augmented written transcripts of audio or video interview recordings by adding barcodes to the paper transcripts. By scanning the barcodes of these 'Books with Voices', the accompanying audio or video file could be accessed directly on a PDA. In relation to our study, bar codes could be used to link physical books to online digital comments about that book.

\subsubsection{Toolkits, technologies and frameworks}

Obviously, augmenting books by integrating digital information requires knowledge of input technologies. To simplify this process, Klemmer et al. [26] created PapierMâché, a toolkit for building tangible interfaces using computer vision, electronic tags and barcodes. Norrie and Signer [27] presented a web-based server technology that supports integration of printed and digital information by allowing users to dynamically link areas of printed documents to objects of an application database. Furthermore, Chien-Meng May et al. [28] proposed a conceptual framework aimed at producing real software and hardware that is designed for the digitally pervasive world. They describe the example of an augmented poetry book and the implications for interaction with this book within its physical, informational and conceptual space. These technologies and frameworks could help to link physical books to digital information related to those books, e.g., a physical book could be used to directly access related comments on a book community Web site.

A well known recent development is the use of e-books and dedicated e-book readers. Currently, most research has focused on e-books in relation to marketing, technology, the design of the readers and the application areas library and education. Only one study on social reading practices related to e-reading is known to the authors, in which e-books are explored as a means to help collaboration [29]. This study has shown e-books could help synchronous sharing in meetings and serendipitous sharing of annotations, providing community-wide anonymous annotations and providing a basis for facilitating interaction between people.

Summarizing, based on other related work, we see that there is a growing interest in (augmenting) physical books and a need for online communication. So far not many studies have focused on combining these two in a new design, which is what we seek to address.

\section{Interview study}

\subsection{Objective}

The goal of our study focused on enhancing a specific type of cherished artifacts, namely books, with a new product, system or service. A study by Csikszentmihalyi and Rochberg-Halton [6] placed books on the fourth place in the list of most cherished artifacts in people's homes. Books were valued for numerous reasons, including reasons related to the self $(22.7 \%)$, experiences $(19.5 \%)$ and personal values (14.5\%) [6], see Table 1. Nowadays, even with online or digitally available texts, statistics show people still buy physical books [8]. Apparently, people still value books, just like they did over 30 years ago. The reasons for valuing books that existed 30 years ago, e.g., enjoyment of reading, memories and embodiment of personal values, still exist nowadays. Therefore, we focused on why rather than whether people value books. The assumption was made was that adults value books more than children or teenagers. This was confirmed by Csikszentmihalyi and RochbergHalton's study [6]: $15.2 \%$ of the children mentioned at least one book as special, compared to $24.0 \%$ of the parents and $25.6 \%$ of the grandparents, which represented a significant difference $(p<0.0002)$. Therefore, our study aimed at adults and the assumption was made that the older you get, the more books you have collected that have meaning. A qualitative interview study was set up to investigate why people value books today. The hypothesis was that the reasons people value books today are approximately the same as 30 years ago, see Table 1. Books still play a role in the every environment of the home, more than for example the internet, because books can be displayed in large numbers while Web sites cannot. This makes books still a good medium for, among others, embodiment and communication of ideals, or memories (displaying books as contemplation objects).

\subsection{Methodology}

The qualitative study consisted of a semi-structured interview similar to Csikszentmihalyi and Rochberg-Halton's 
Table 1 Distribution and percentages of the meaning classes, or reasons for valuing, for books [adapted from Csikszentmihalyi and Rochberg-Halton 6, p. 88]

\begin{tabular}{llrr}
\hline Meaning class & Examples in this class & $N$ & $\%$ \\
\hline Self & Respondent is an explicit reference of the book & 58 & 22.7 \\
Experiences & Enjoyment, release, ongoing occasions & 50 & 19.5 \\
Personal values & Ideals, accomplishments, personification & 37 & 14.5 \\
Memories & Memento, recollection, heirlooms, souvenirs & 29 & 11.3 \\
Associations & Ethnic, religious, collections, gifts & 22 & 8.6 \\
Immediate family & Spouse, children, parents, siblings & 19 & 7.4 \\
Utilitarian & Convenience, saving time, saving money & 14 & 5.5 \\
Nonfamily & Friends, associates, role models & 11 & 4.3 \\
Intrinsic qualities & Craft, uniqueness, physical description & 10 & 3.9 \\
Kin & Relatives, ancestors, in-laws & 3 & 1.2 \\
Style & Fashion, decorative, design aspects & 3 & 1.2 \\
Total & & 256 & 100.0 \\
\hline
\end{tabular}

study [6], with the difference that our study aimed only at books. Each interview took approximately $1 \mathrm{~h}$ and was held in the respondent's home. Several days before the interview, the respondent was asked to select three to five books that were special to him or her. These books were used as input for the interview. Questions in the interview addressed: approximate number of owned books, number of valued books, reasons for valuing books, location of books in the home, and acquisition of valued books (why, how and when).

Respondents were recruited on an individual basis. Criteria for participation included attachment of some value to books, adult, Dutch. The respondents were asked whether they valued books before being selected to participate. Data were collected through: written notes on the semi-structured interview; audio recordings of the interview to allow capturing all comments and at the same time allow for more contact between interviewer and respondent; and photographs taken of the respondent's selected books and main book locations, such as book shelves in the living room.

\subsection{Coding process}

To allow better comparison, the answers to the interview questions were analyzed using a closed coding method. Closed coding is a suitable analysis method when there is a clear hypothesis containing categories for the gathered discrete qualitative or categorical data [30]. The coding categories were derived from Csikszentmihalyi and Rochberg-Halton's study [6], see Table 2. The coding process was divided into four steps: $1-$ All interviews were coded for all categories, except for 'Self'. This category was excluded in the first step, because it was a category that overlapped others and it would obscure the coding results; 2-All coding categories were run through to check if all references were in the right category, e.g., is this really what the respondent means? References were added to other categories if applicable, double or similar references to the same object in one category were removed, and doubtful or unclear references were coded in separate coding categories, outside of the framework; 3-All interviews were checked for 'forgotten' references, including references to 'Self'; 4-All coding categories were run through once again to see if all references really indicated a reason for valuing a book. The separate coding categories were fit in the framework, e.g., with subcategories.

In step 2 of the process, three separate coding categories were created for groups of references that did not fit directly in the framework: $1-\mathrm{New}$ code: Belongs to me: includes descriptions of books that are stated 'to belong to' or 'are part of' the respondent's person or period of life, e.g. "That is my youth"; for example:

"I will never throw this away. You could say, you have two copies now (respondent had recently bought another copy of the book), you can throw away the old one, because it has no table of contents anymore, and it is read to pieces. But I will not throw it away, because it is the book of memories. I just need to have this; this belongs to me, this read-to-pieces book of fairy tales." (Respondent about the book of fairy tales: 'De Verhalenreus')

2. New code: Identification: Includes descriptions of identification with the main character, story or certain things that happen in the story; for example:

"This interests me, because it is about oppression of women. I can relate to that because I am a woman myself and I can identify with the older woman in the book." (Respondent about Khaled Hosseini's 'A Thousand Splendid Suns') 
Table 2 Coding categories and codes used for analysis; 'Coding categories' and 'Codes' from Csikszentmihalyi and Rochberg-Halton [6]

\begin{tabular}{|c|c|c|c|}
\hline & Coding categories & Codes & Additions \\
\hline \multirow[t]{4}{*}{ Person codes } & Self & Self & \\
\hline & Immediate family & $\begin{array}{l}\text { Spouse, we, children, parents, siblings, } \\
\text { grandparents, grandchildren, whole } \\
\text { family (nuclear) }\end{array}$ & \\
\hline & Kin & Relatives, ancestors, in-laws & \\
\hline & Nonfamily & $\begin{array}{l}\text { Friends, associates, role models, heroes, } \\
\text { admired people }\end{array}$ & \\
\hline \multirow[t]{9}{*}{ Non-person codes } & Memories & $\begin{array}{l}\text { Momento, recollection, heirloom, } \\
\text { souvenir, "Had it for a long time" }\end{array}$ & \\
\hline & Associations & Ethnic, religious, collections, gift & \\
\hline & Experience & Enjoyment, ongoing occasions, Release & Interests, fascination, flow \\
\hline & Intrinsic Qualities & Craft, uniqueness, physical description & Additions, changes \\
\hline & Style & Style & Style of writing \\
\hline & Utilitarian & Utilitarian & \\
\hline & Personal values & Embodiment of an ideal & Sub-code: identification \\
\hline & & Accomplishment & Sub-code: personal growth \\
\hline & & Personification & Sub-code: belongs to me \\
\hline Acquisition codes & & $\begin{array}{l}\text { Purchased, gift, inherited, crafted, found, } \\
\text { award, hand-me-down, traded, moved } \\
\text { into house, other }\end{array}$ & \\
\hline
\end{tabular}

3. New code: Personal Growth: Includes descriptions of change in ideas or way of thinking, growth in life or person and being shaped by the book(s), for example:

"When I had finished reading this book I felt I had to read many more books to understand what the author meant. This book was a trigger: I was filled with energy to study and read. It made me realize the importance of reading for me. I will never forget that." (Respondent about Hermann Hesse's 'Glasperlenspiel')

These new codes were fitted in the framework by means of sub-codes of the existing codes in the coding category 'Personal Values': 'Belongs to me' became a sub-code of 'Personification', because this code already included references to the object having a quality of personhood. 'Identification' became of sub-code of 'Embodiment of ideals', because embodiment of ideals can result in identification. 'Personal Growth' became a sub-code of 'Achievement', because respondents talked about this growth as something they had achieved and were proud of.

Furthermore, some coding categories were explicitly expanded with some groups of found references: 1 Addition to Experiences-Enjoyment: Includes descriptions of books that have to do with something that interests the respondent, gripped or fascinated him or her, and descriptions of 'not wanting to stop reading' (flow feeling); 2 Addition to Intrinsic Qualities-Craft: Includes additions or changes made to the book by respondents, which are stated to give an additional value, e.g., notes and comments in a cook book; 3 Addition to Style-Style: Includes descriptions of style of writing, e.g., clear, compact, or poetic and use of language. In Table 2, the initial codes from Csikszentmihalyi and Rochberg-Halton [6] and our additions can be seen.

\subsection{Results}

\subsubsection{Respondents}

Nine Dutch adults participated in the interview study ( 5 women, 4 men), average age 50.4 years (ranging from 47 to 55). Education levels of the respondents were mixed: 3 respondents had had lower general secondary education (MAVO), 2 respondents had had intermediate vocational education (MBO), 3 respondents had had higher vocational education (HBO), and 1 respondent had had an academic education (university).

Respondents owned an average of 403 books, estimations ranging from 50 to 1,500 , which were divided as shown in Fig. 1. Respondents indicated to consider an average of 134 books special books, ranging from a very small part of their collection to almost all of them. Most participants (6 out of 9) considered 50 or less books special.

The average time spent reading, studying or looking in books was $7.9 \mathrm{~h}$ per week, ranging from 1 to $20 \mathrm{~h}$ per week. Some respondents indicated that time spent reading 
Fig. 1 Numbers of all books respondents owned and numbers of books they considered special

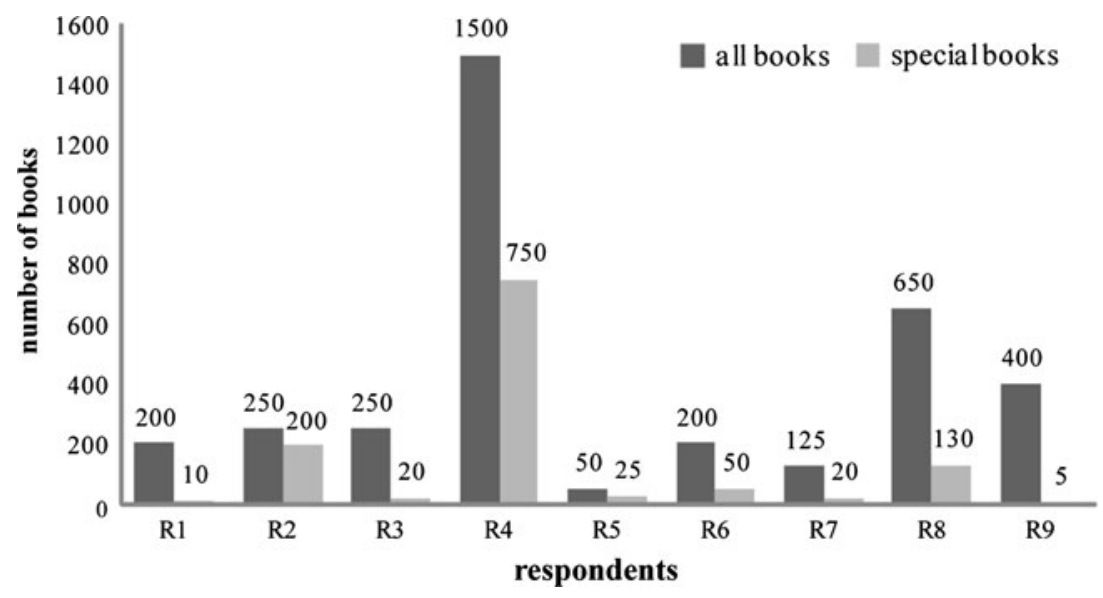

Table 3 Division of special books over content categories

Category

$\%$ of special books

Novels $-\ldots$ Refence books $\left\{\begin{array}{lr}\text { hobby/activity books } & 20.9 \% \\ \text { history books } & 7.0 \% \\ \text { science books } & 7.0 \% \\ \text { dictionaries } & 4.7 \% \\ \text { study books } & 2.3 \% \\ \text { novel/reference book } & 2.3 \%\end{array}\right\} 44.2 \%$

Children's books $-----------4.7 \%$

Bibles - - - - - - - - - - - - 4.7\%

"I like cooking something special a couple times a week and each week I look for new recipes on the internet, in magazines and in my cook books. I have many cook books, but this is a wok book: fast, healthy and very tasteful." (Respondent about "Het beste Wadjan/Wok kookboek' (The best Wadjan/ Wok cook book))

Experience, for example:

"This book teaches me the names of bugs and where to find them. That is something I have always liked a lot, being in nature, looking for something and identifying it. Later, I specialized in spiders and bees, but bugs in general are very interesting to me." (Respondent about 'De grote encyclopedie der insekten' (The complete encyclopedia of insects))

And Personal Values, for example:

"This book is an extension of my brain: there is so much I don't know and can't remember. When I was a child my father taught me to look up everything I don't know. You don't have to know everything, as long as you know where to find it." (Respondent about 'Polytechnisch zakboekje' (Polytechnic handbook)) 
Fig. 2 Pictures of book collections and selections of special books taken at respondents' homes
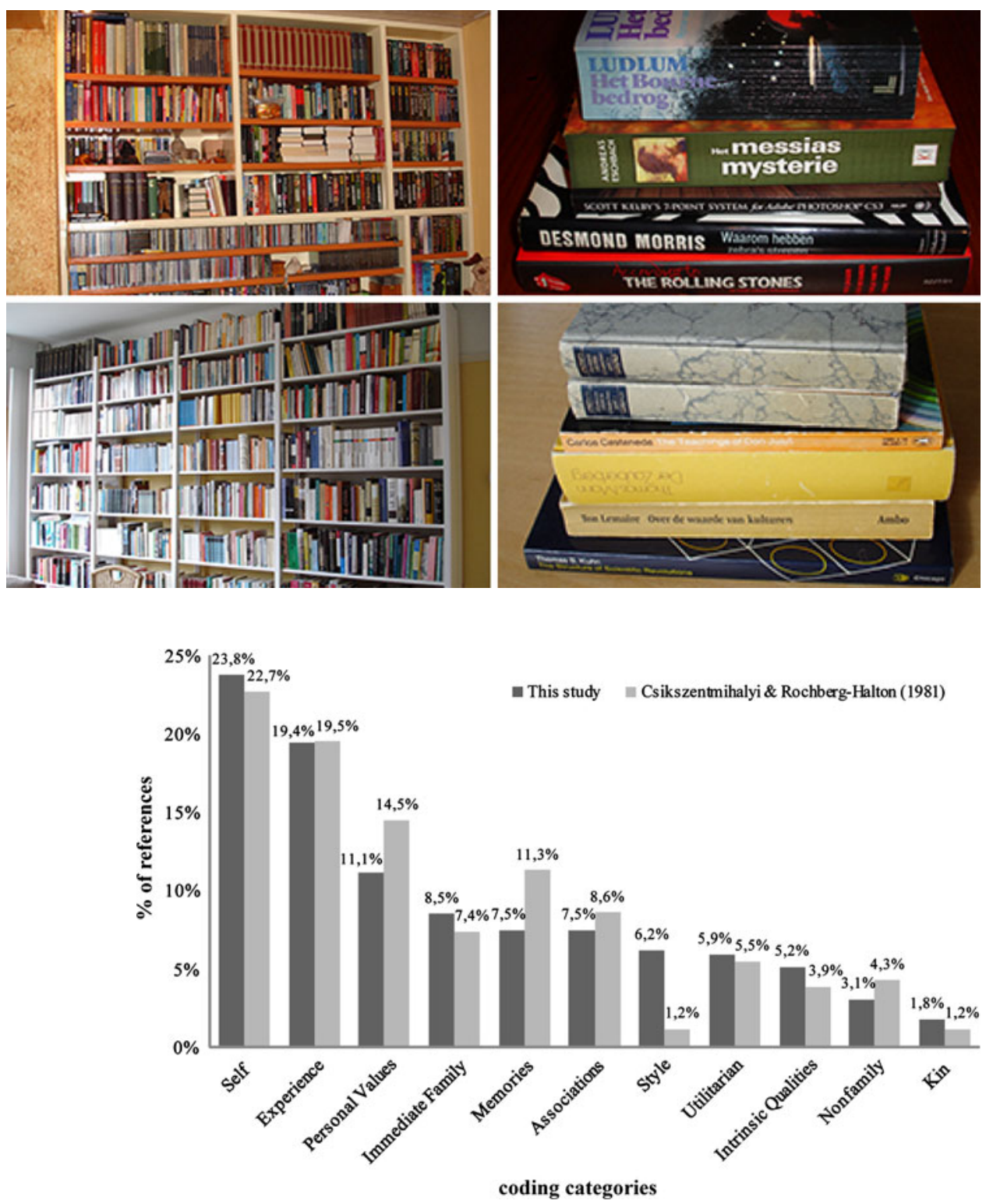

Fig. 3 Percentages of statements in the separate meaning categories in our study and in Csikszentmihalyi and Rochberg-Halton's study [6]
These reasons were followed by Immediate Family, Memories and Associations. The results were compared to Csikszentmihalyi and Rochberg-Halton's results [6], see Fig. 3. The division of references over the different codes within Experience and Personal Values can be seen in Fig. 4.

\subsubsection{Other book formats}

The interview also included questions about other formats of books, such as e-books and audio books. This also included books that were not owned by the respondents themselves, because they were borrowed or library books. Respondents were asked whether they had used any of these other formats, whether there were also valued books among these other formats and how the value of these books differed from that of books they owned themselves.

All respondents had experiences with library books and borrowed books. Although some respondents mentioned some special books among these, this mostly related to the contents of the book, not the specific book. In general, library books and borrowed books were considered less special as it was the story behind the books that seemed to matter most, for example childhood memories associated with the book, or because the book was a souvenir. Most respondents agreed that if a borrowed or library book was special to them, they would buy it themselves. One respondent indicated to use library books as a pre-selection for which books to buy. Another respondent explained to have a special relation with the books he had physically 
Fig. 4 Division of the references over the separate codes within the coding categories: left Experience and right Personal Values. For personal values the sub-codes are included
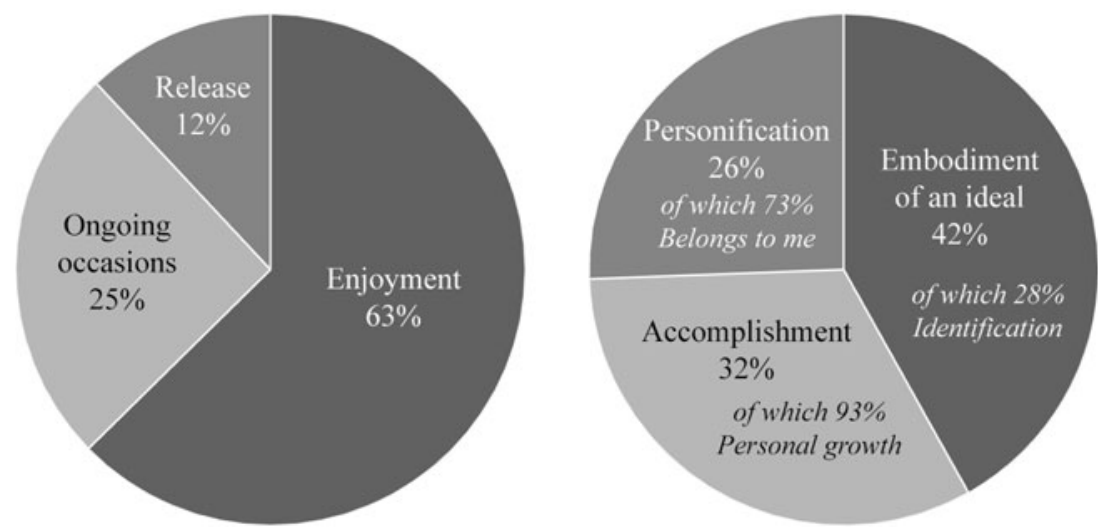

read, so when he bought a book after reading a borrowed version and he had not read that specific book, it would not mean that much to him.

Only one respondent had experiences with audio books. He considered these a completely different medium and valuable due to their additional characteristics, such as different voices and sound effects.

Three of the respondents had experiences with e-books, and they all agreed that use of e-books was primarily utilitarian. E-books were considered very useful because they were relatively cheap (usually respondents only needed small parts of a book), easy to take along on a laptop, and it was fast and easy to find a specific piece of information. For recreational reading, e-books were not considered valuable, because respondents preferred to sit down with a physical book. Therefore, e-books were solely used as reference books, mostly in work context, and none of the special books were e-books. Note: at the time of this study, there were no e-readers yet on the Dutch market and respondents did not have experiences with these. The use of e-readers may influence respondents' opinions on e-books.

\subsubsection{Discussion, comparison and conclusion}

When comparing the reading behavior of the respondents in the interview study to the book customs of the average Dutch adult, a difference can be seen that needs to be taken into account in context of this study. The average time respondents of the interview study spent reading, studying or looking in books was $7.9 \mathrm{~h}$ per week. This is much higher than the Dutch average of less than $4 \mathrm{~h}$ per week in 2005 [8]. This indicates that the respondent sample in our interview included people with more affection for books than the national average. This was desirable for our study, but it may be the case that our design is not generalizable over the whole population.

In this analysis and comparison to the results of Csikszentmihalyi and Rochberg-Halton's study [6], there are some considerations to be mentioned. First of all, all statements in the interview study were considered independent observations for this analysis, while in fact there were only nine independent observations for the nine participants in the study. When taking all statements, clusters of answers from the same person will arise, since one person may be more likely to give a certain answer than another. This effect was neglected in the analysis. Secondly, when setting up an experiment, it is important to calculate beforehand the size of the sample. Since the interview study's aim was to be qualitative, this was not done. As a result, the small sample size may have influenced the power of discernment and the reliability of the comparison between our study and Csikszentmihalyi and Rochberg-Halton's study. It is possible that in some categories, more references were found because particular respondent(s) were more likely to address these categories, which may have influenced the results.

In the study by Csikzentmihalyi and Rochberg-Halton, 79 books were mentioned as special and they coded 256 references; this comes down to 3.25 references per book on average. In this study, 43 books were mentioned as special and 389 references were coded, which seems to come down to 9.0 references per book on average. The question arises what caused this difference. First, unlike in Csikzentmihalyi and Rochberg-Halton's study, in this study respondents talked about more books than the 4 or 5 they selected, because interview questions also included references to other special books, e.g., special books that were no longer in the respondent's possession, private or personal books and the book collection as a whole. Therefore, the actual average of references per book is less than 9.0. Second, asking respondents explicitly for special books, instead of special artifacts, may have elicited more books to be mentioned and more meanings to have occurred to respondents. It is likely respondents did not only mention the most important reasons for valuing their books, but also additional, secondary reasons. Because this study aimed at finding rich data on the reasons for valuing books, this was desirable. 
This study has shown the reasons people have for valuing books, which are primarily Self, Experience and Personal Values, followed by Immediate Family, Memories and Associations. A comparison was made to the 1981 study by Csikzentmihalyi and Rochberg-Halton [6] (see Fig. 3), by looking at the distributions of the statements over all the coding categories. It appeared the difference between the distribution in our study and the distribution in Csikzentmihalyi and Rochberg-Halton's study was not significant $\left(\chi^{2}(10)=15.33 ; p<0.05\right)$. This indicates the reasons people have for valuing books today are not significantly different from the reasons people had almost 30 years ago, which confirms our hypothesis.

When comparing the percentages for each separate meaning category in both studies, there were significant differences in the following categories: Style $(t=-4.90$; $p<0.05)$, Intrinsic Qualities $(t=-2.98 ; p<0.05)$ and Kin $(t=-7.51 ; p<0.05)$. For the Style category, this difference could be caused by including style of writing in this category in our study. It is possible Csikzentmihalyi and Rochberg-Halton did not get many references to style of writing. When selecting a book as special among all other artifacts, as in Csikzentmihalyi and Rochberg-Halton's study, probably a person is less likely to indicate style of writing than when selecting it among other books, as in this study. It could also be that Csikzentmihalyi and RochbergHalton included style of writing in another category without mentioning this explicitly. There was no data of the number of references in the separate codes within the coding categories in Csikzentmihalyi and Rochberg-Halton's study, so this comparison could not be made. Differences in the Intrinsic Qualities could be explained by the exclusion of crafted items, e.g., self-written books and scrap-books and physically unique items like photo-albums. Differences for the Kin category could be explained by the surprisingly absent references to the code Ancestors in our study. The respondents did mention parents and grandparents, which had their own codes within the Immediate Family category, but did not mention other ancestors. More quantitative data are needed to test whether the differences for the Style, Intrinsic Qualities and Kin categories are also significant outside our sample. In conclusion, the reasons for valuing books today were found to be not significantly different from almost 30 years ago, although some differences could be seen in the categories Style, Intrinsic Qualities and Kin.

\section{Idea generation and concept development}

\subsection{Idea generation}

After investigating the reasons for valuing books, ideas were generated for an enhancement of books or book collections that focused on strengthening those characteristics that make people value books. To generate these ideas, a method of word association and forced relations was used: for each idea three words that were not directly related, were combined and used to create an idea based on associations with the words. These words were derived from references coded in the three highest categories for valuing books: Self, Experience and Personal Values. For each category, words characterizing that category or subcode were selected as brainstorm input. Examples of words from the different categories are as follows: Self: different world, inspiration, identification, youth, being alone; Experience: interests, memories, dreaming away, excitement, talking about it; Personal Values: learning, recommending, looking up, getting to know yourself, physical connection. Ideas were generated per category, so words from category Self were only combined with other words from Self. By combining three words for each idea, over 30 ideas were generated.

All ideas were checked for feasibility and relevancy and combined into seven interesting idea directions: 1 Private reading experience: a-let the book accommodate it when you want to be isolated to read, and b-let the book help you to get back into the reading experience by helping to recollect the previous reading experience, e.g., with sound cues. 2 Information display: an interactive table or book stand that displays information about the book, e.g., related books, recommendations, mental links (photos etc.). 3 Social contacts with friends: a-get recommendation from friends about books, $b$ - have direct contact with your friends by means of a network system, and c-know what your friends are reading. 4 Adjustable collection: a) detect the interests of a visitor and highlight books that may interest him or her, and b) multi-layer closet which allows displaying only books interesting to the visitor. 5 Personal book history: the personal history of a book is displayed, because it is the story behind it that matters. 6. Keep track of your collection: some token to help you to keep track of your collection, you can take it to the bookstore to check your wish list. 7. Readers' traces: a-leave comments in a book for the next reader (e.g., someone who borrows it or a next generation), b-interactive bookmark to make notes, and $\mathrm{c}-$ small, inexpensive, removable hidden messages.

\subsection{Concepts}

The seven idea directions were checked again with the interview study results in mind. Each idea was evaluated with the respondents' answers regarding the value of books and reading experiences as a starting point. Based on this evaluation, four ideas were selected to be worked out and used in a user consultation: information display, social contacts with friends, personal book history and readers' 
traces. These ideas were developed into the following concepts.

1 Information stand: The information stand is a system with which information about books can be looked up immediately, e.g., information about the author, similar books or reviews. By placing the book on the information stand it is recognized and the information is displayed right away, see Fig. 5a.

2 Reading network: Reading network is a system with which friends or family members have direct contact with each other and can share information about their books. A small device on the book shelf shows what books friends are reading and their comments on these books. The reader can adjust his choice of book to this information, for example when he or she wants to discuss a book with a friend, see Fig. 5b.

3 Book history: The book contains a visualization of its own history, for example where it has been read and by whom. This visualization is updated automatically when the book is opened on the history page: pictures are taken from the inside and outside of the book to show the reader and the surroundings. These pictures are added to the history, see Fig. 5c.

4 Readers' traces: Readers' traces is a system with which readers can leave messages and comments in a book for later readers, either themselves or others (e.g., people who borrow the book or later generations), in an accessible, transitory and obligation-free way, see Fig. $5 \mathrm{~d}$.

\subsection{User consultation}

The four remaining concepts were discussed with a test group of five people within the target group (3 women, 2 men, aged 47-53, and mixed education levels, ranging from lower general secondary education to academic education) to gather feedback on the concept functionalities. Each respondent was shown the concept drawings and interviewed individually. The concepts were discussed one by one, and the small interview for each concept consisted of questions addressing the respondent's general opinion about the concept, perceived added value to traditional books, whether the respondent would use it, and possible improvements or changes. Respondents were further asked to determine their order of preference for the four concepts.

All in all, the information stand functionality appeared most interesting to the test group, although in all concepts interesting functions were found. Some desired functionalities the respondents expressed were information about what the book is about: more elaborate information than is available on the back cover; making private comments (e.g., summaries, when it was read and opinions) and the possibility to include the text it is referring to; adding information about how the book was acquired, e.g., bought or a gift, when, where, from whom; comments from and for others on the book (most users preferred this on a global level: comments on all books in one device, rather than per book or even per specific place in a book); knowing what
Fig. 5 Concept drawings for: a information stand, $\mathbf{b}$ reading network, $\mathbf{c}$ book history, and d readers' traces

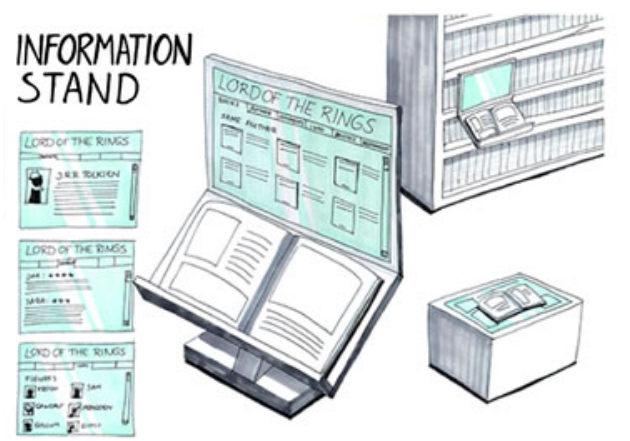

a

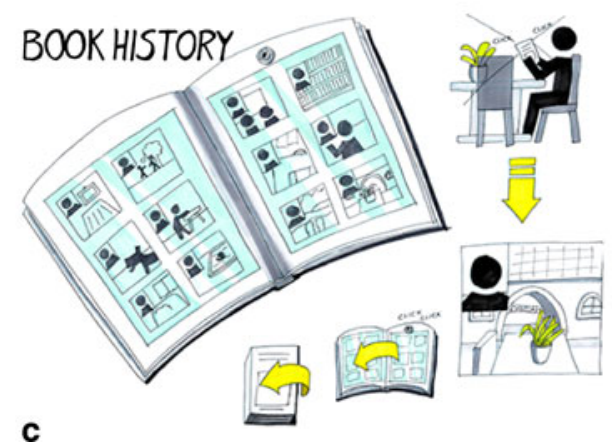

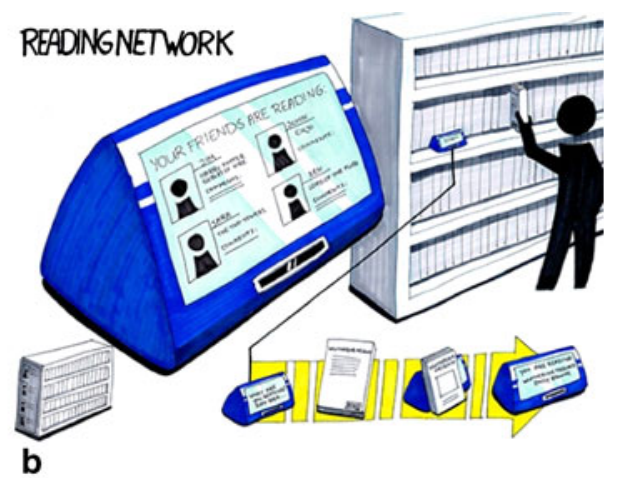

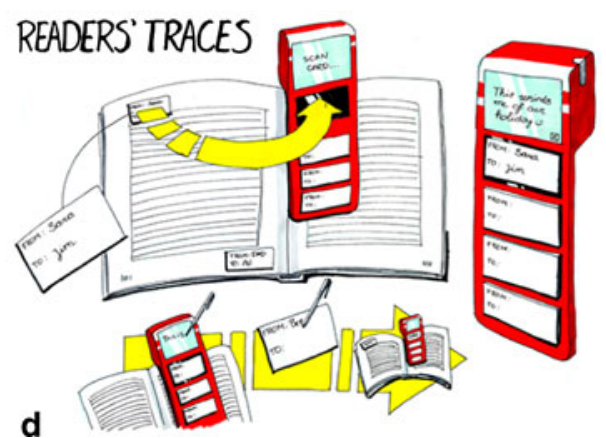


friends are currently reading and what they have read; recommendations for and from friends; personal reading history; and portability: take the device to friends, library or store and directly add books or look up books to read and recommendations. Respondents further commented that they would take the time to add books and comments to a communication system if the books made an impact on them and they were worth recommending. Three main functions derived to enhance books were 1 book information; 2 social comment network; and 3 reminder of what books they had read and what they were about (personal notes).

From these main functions, it was decided to focus on the social comment network, because it was the aspect respondents expressed most interest in, in varied specific features. Furthermore, the social network formed an interesting contrast with the results found in the interview study that books mostly have to do with the Self. Reading experiences are often primarily individual, but nevertheless social communication about books is valued by many readers.

To test the social network functionality, it was decided to design, implement and use a web-based system that incorporated the functionality of the social network. This system was used in a 14-day user evaluation, in which the participants got a better idea of actually using the system. The participants in the study were friends or acquaintances of each other so the actual functionality closely resembled offline social book networks.

\section{Design and implementation}

To facilitate the social book network a Web site, called Shelf, was implemented, in which participants could create their own book list, and send messages and recommendations (small notifications to one friend).
Furthermore, they could see what books friends had in their book lists and what their read state for each book was (read, not read, or reading). The Shelf Web site consisted of a back-end for administrator purposes and a front-end for the participants.

\subsection{Back-end}

At the back-end of the Web site, the administrator could $\log$ in and manage the participant information. Here participants could be added to the network or removed, participants' data (name, address, etc.) could be changed and participants could be linked to others in the network (indicated as buddies). Furthermore, an overview of participants in the network could be found, including their number of logins, books, messages and recommendations.

\subsection{Front-end}

The front-end was the Web site as the participants encountered it. Each participant in the evaluation had his or her own password which could be used to log in. The Shelf Web site consisted of four main pages: books, messages, buddies and profile. 1 books: This page gave an overview of the participants' books and new books could be added. Information and messages about a specific selected book could be found and the read status could be changed; see Fig. 6a. 2 messages: This page gave an overview of the sent and received messages. There were four parts: new message, inbox, outbox, and recommendations (sent and received recommendations); see Fig. 6b. 3 buddies: This page gave an overview of the participants' friends and their book lists. Information and messages about a specific buddy or buddy's book could be viewed. 4 profile: On this page, the participants profile could be changed and a picture could be uploaded.
Fig. 6 Screenshots of the Shelf Web site: a books section and b messages section
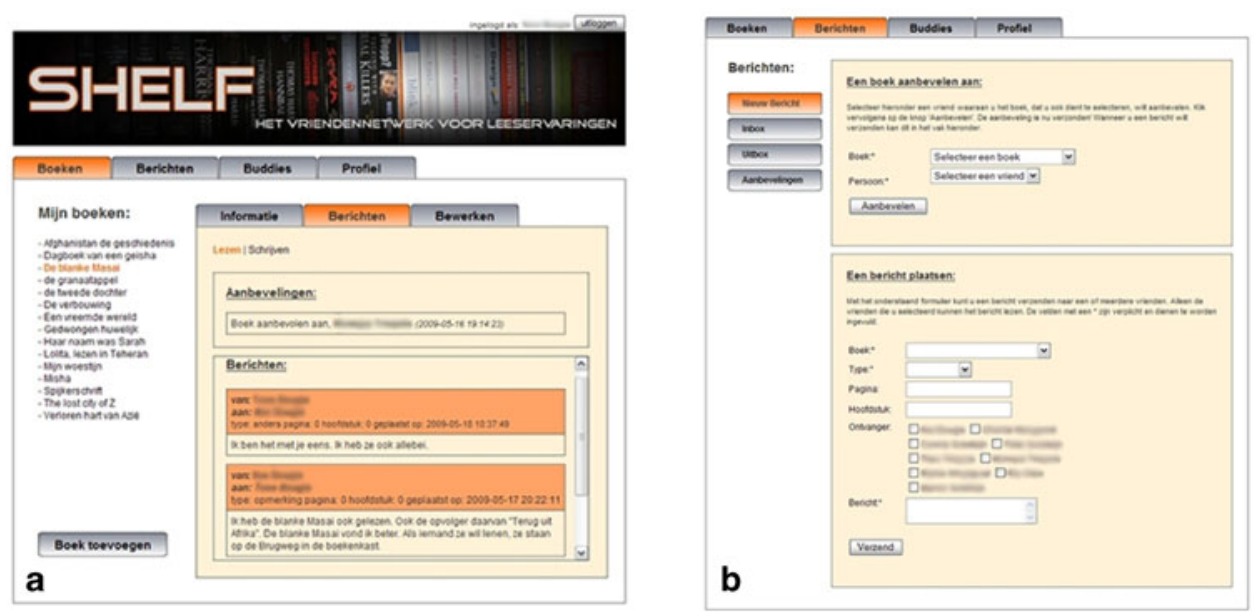


\subsection{Database}

The Web site was implemented using PHP and HTML, and the underlying database management was MySQL based. The database model can be seen in Fig. 7. In this model, a book is linked to a person through the person_book table, which links the bookIDs to the personIDs, each with a read status. Naturally, one person can have more than one book, and one book can be in the list of more than one person. Furthermore, a person can have a number of friends, which can be the friends of more than one person and to each person-book combination a number of messages can be linked: a message that a specific person sends about a specific book. Lastly, the log table stored when a person logged in on the Web site.

\section{User evaluation methodology}

The Shelf Web site was used in a user evaluation to study communication about books. In this evaluation, eight Dutch adults (6 women, 2 men, average age 49.3, and mixed education levels, ranging from intermediate vocational education to academic education) used the Shelf Web site for 14 days. The participants in this evaluation were not involved in the earlier interview study or concept consultation and did not know the goal of our study. Apart from the interaction with Shelf, the user evaluation consisted of a 'before' questionnaire, filled out by respondents without or before the intervention of the Shelf Web site, and an 'after' questionnaire, filled out by the participants after using Shelf in the evaluation period. The 'before' questionnaire was used to collect information about current book communication, e.g., frequency, content and was used for comparison with the results of the 'after' questionnaire.

All in all, the evaluation consisted of: 1 initial meeting with the participants, which consisted of an explanation of the system and evaluation, signing consent forms, and the 'before' questionnaire; 2 using the system in the evaluation period; during the evaluation period the participants could contact us if they had questions, but no interference took place; 3 second meeting with the participants, which consisted of the 'after' questionnaire and thanking the participants. The main research question was does a social book network, like the designed system, increase communication about books? Furthermore, a number of sub-questions were asked, namely 1 Would the target group consider the (increased) communication about books beneficial? 2 To what extent would the target group use the Shelf Web site? 3 Would the Shelf Web site elicit more communication about books? 4 What information would be communicated through the Shelf Web site? 5 What information would the target group want to receive from, and give to, their friends who are using the same online community?

\section{1 'Before' questionnaire}

The 'before' questionnaire consisted of 12 multiplechoice questions, addressing frequency of communication, communication media, involved persons, initiation of communication, content of communication, result of communication (what do they do with the information), relevancy and important information to give and receive. To increase the size and reliability of the 'before' sample, the questionnaire was filled out by both the 8 participating in the Shelf evaluation and 15 other respondents. Of these 23 respondents, 15 were women (65.2\%). All
Fig. 7 Database model for the Shelf Web site

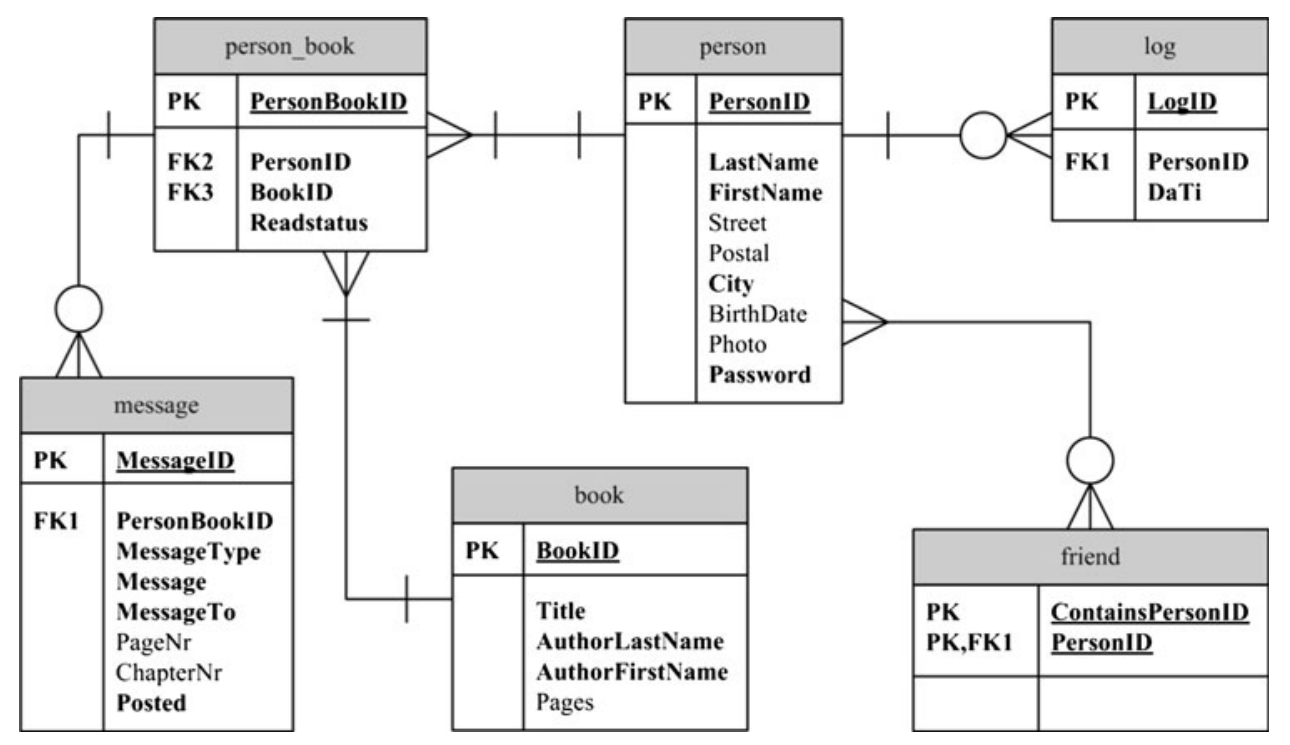


Fig. 8 Perceived significance of book communication in the 'before' and 'after' groups

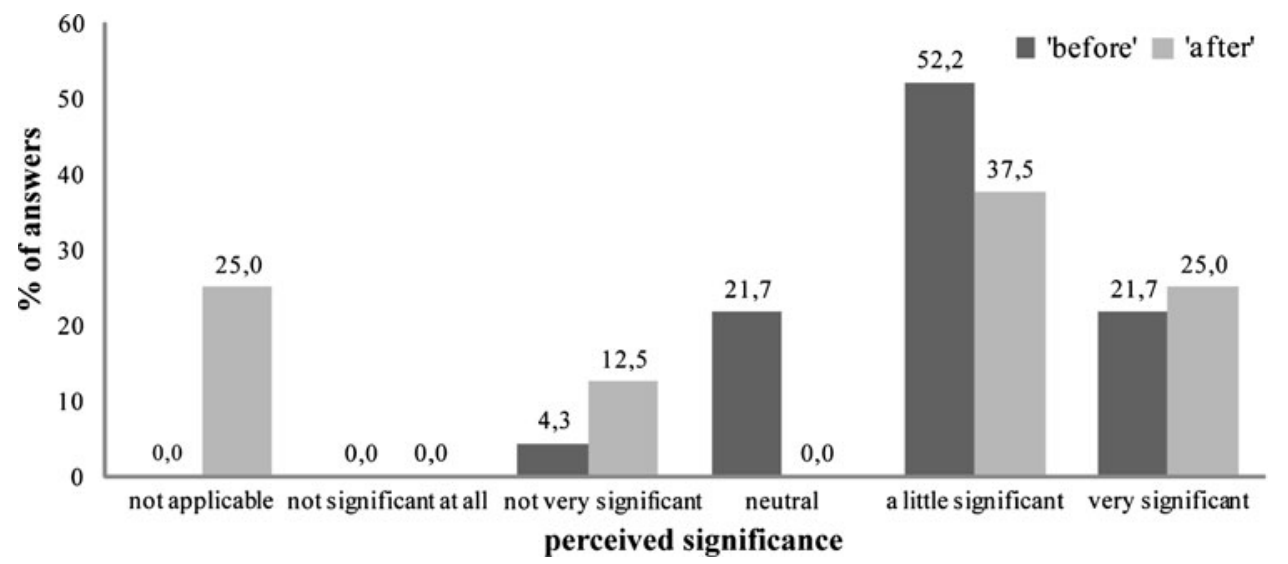

were Dutch adults (95.6\% employed), ages ranged from 22 to 60 , with an average age of 45.7. Education levels ranged from lower general secondary education to academic education, with higher vocational education as the most common level.

\section{2 'After' questionnaire}

The 'after' questionnaire was filled out by the 8 participants of the Shelf evaluation ( 6 women, 2 men). Ages ranged from 44 to 55 , with an average of 49.3. Levels of education were divided as follows: 4 participants had had intermediate vocational education, 3 participants higher vocational education and 1 participant an academic education. In the 'after' questionnaire, the same multiple-choice questions were asked as in the 'before' questionnaire, to be able to compare the answers. In this questionnaire, the respondents were asked to answer these questions about the evaluation period. In addition, five open questions were asked, addressing: perceived change in communication, attractiveness of the functionalities Shelf offered, the most important functionality, improvements and whether they would use, or keep using Shelf.

\section{User evaluation results}

\subsection{Would the target group consider the (increased)} communication about books beneficial?

When asked about the significance of book communication, $73.9 \%$ of the 'before' group answered they considered book communication at least a little significant $(21.7 \%$ found it even very significant) against $62.5 \%$ of the 'after' group, of which $25 \%$ found it very significant, see Fig. 8.

When asked whether they considered the communication through Shelf pleasant, four of the eight participants answered they considered communication through Shelf at least a little pleasant, of which 1 participant found it very pleasant. Three others were neutral and one did not answer this question. Several participants (4 out of 8 ) agreed the evaluation period was too short to 'really get into it', but all agreed it was nice to see others' opinions and book lists and get aware of unknown books. One participant added "I am not much of a talker and this way I can still exchange information with others."

7.2 To what extent would the target group use the Shelf Web site?

Web site loggings were stored and studied to see the activities of the participants on the Shelf Web site during the evaluation period. Information was gathered about the number of logins, books, messages and recommendations, see Fig. 9.

\subsubsection{Logins}

In total, all participants together logged in 63 times during the evaluation period. This was divided over 34 times in the first week and 29 times in the second week. When looking at even smaller periods, it can be seen that in the first 4 days the number of logins was highest: 20 times. In the remaining three blocks of 3 or 4 days, the number of logins was approximately stable, with respectively 14,14 and 15 times. This indicates that after the initial experiences, the Web site remained quite interesting at least for a period of 14 days. The maximum amount of logins by one participant was 20 and the minimum 2, with an average of 7.9 times, see also Fig. 9.

\subsubsection{Books}

In total, 98 books were entered by the participants, of which 72 had the read state 'read', 18 had state 'not read' and 8 had state 'reading'. Of the 98 books, 58 only existed in the book list of one participant, 17 existed in the book lists of two participants and 2 books in the lists of three 
Fig. 9 Numbers of sent messages and recommendations, books and logins per participant

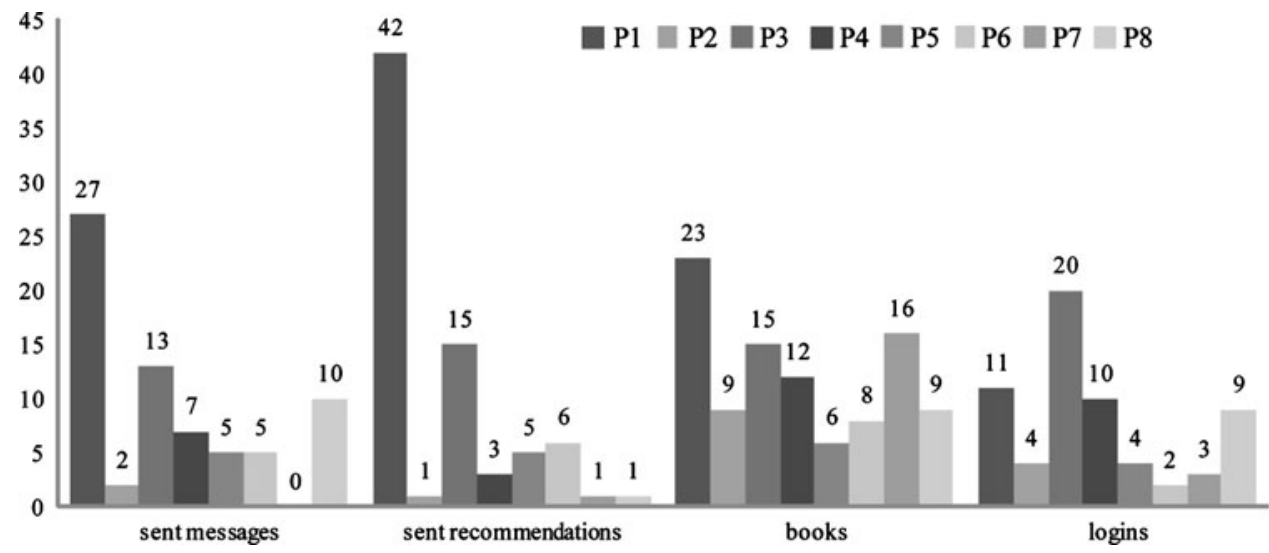

participants. So there were 77 unique books entered. Messages and recommendations were sent about 47 different books, so about approximately $60 \%$ of the books. The other $40 \%$, while not being subject of communication, could still have triggered or inspired others. The maximum amount of books in a participant's list was 23, the minimum 6, with an average of 12.3, see Fig. 9.

\subsubsection{Messages and recommendations}

A recommendation is a special message kind that can only be sent to one friend at a time and always has the same format: " 'sender' recommends 'book title' to you". In total, 74 recommendations were sent. The maximum of recommendations sent by one participant was 42 and the minimum 1, with an average of 9.3. In total, 69 messages (excluding recommendations) were sent. The maximum of one participant was 27 and the minimum 0 , with an average of 8.6. In Fig. 9, the numbers of sent messages and recommendations can be seen.

Next to Web site loggings in the 'after' questionnaire, participants were asked whether they would use, or keep using, Shelf if it was an existing service. Answering this question, 6 out of 8 participants said yes, of which 3 added the requirement of communicating with a group of known buddies. Reasons to keep using Shelf were to get new recommendations and reviews from friends and get aware of other interesting books. A reason for not using it was that it was considered too laborious by one participant and one participant indicated not being 'computer-minded'.

\subsection{Does the Shelf Web site elicit more communication about books?}

When comparing the answers in the 'before' and 'after' questionnaires, a conclusion can be drawn on frequency of communication. In the 'before' questionnaire, most participants $(56.6 \%)$ communicated about books on a weekly basis, with average of 1.5 times a week. The total average was 51.7 times a year, which comes down to approximately once a week. In the 'after' questionnaire, frequency of communication over the evaluation period (14 days) varied from 0 to 25 with an average of 8.5. This comes down to 4.3 times a week. It should be noted however that in this case the participants were explicitly asked to use the Web site and communicate about books, and the evaluation period was only 14 days. A popular communication media in both groups was face-to-face communication $(95.7 \%$ of the 'before' participants used this and $62.5 \%$ of the 'after' participants used this within the evaluation period), although the most used medium in the 'after' group was the Shelf Web site (used by $87.5 \%$ ).

Upon the question in the 'after' questionnaire whether their way of communicating was changed by using the Web site, opinions varied greatly: 1 participant said 'not at all', while 'not much', 'neutral' and 'a little' were each chosen by 2 participants. Some participants thought the communication about books would have taken place also without Shelf, while many agreed it was a quick and convenient new possibility for book communication. Furthermore, participants indicated to be more actively and consciously involved with book communication because of Shelf, through Shelf and also through other means, such as face-to-face communication.

\subsection{What information would be communicated through} the Shelf Web site?

Most common topics in book communication in the 'before' group were books read by one of the communicators $(87.0 \%)$, recommendations $(78.3 \%)$ and books by specific authors $(73.9 \%)$. In the 'after' group, the same topics scored highest, only the order was somewhat different: recommendations $(75.0 \%)$, books by specific authors $(75.0 \%)$ and books read by one of the communicators $(62.5 \%)$. It appears the same information is communicated with and without Shelf, although participants indicated the Web site formed a convenient means to 
Fig. 10 Topics respondents in the 'before' and 'after' groups indicated to communicate about. Respondents were asked to indicate all topics they communicated about

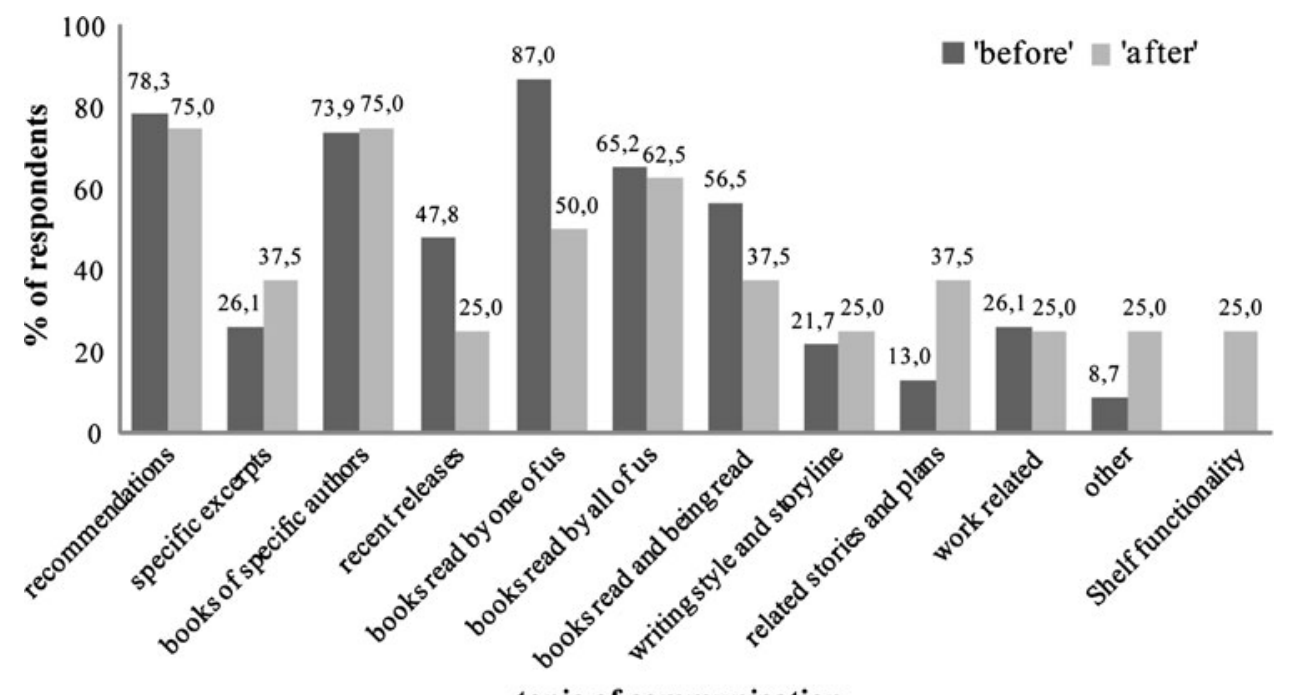

topic of communication

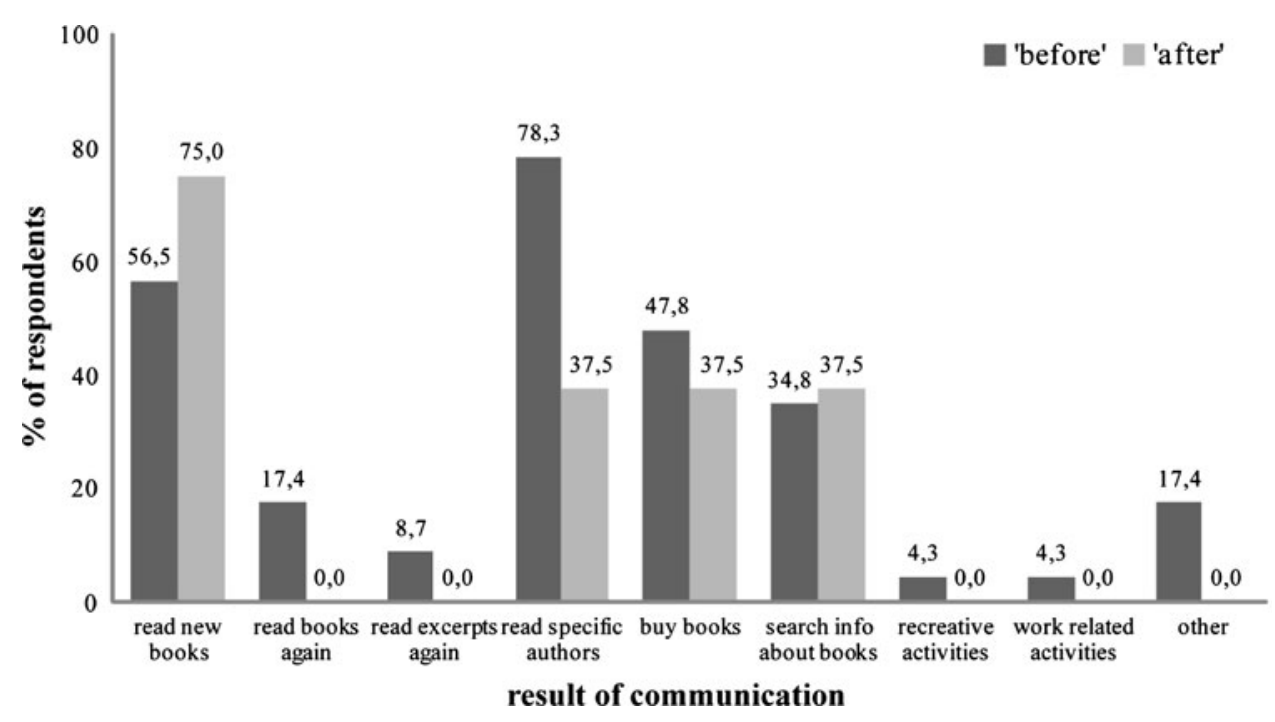

Fig. 11 Actions that resulted from communication in the 'before' and 'after' groups. Respondents were asked to indicate all actions that resulted from book communication

communicate. An overview of communication topics can be found in Fig. 10.

A common result of book communication in both groups was reading new books ('before': $56.6 \%$, 'after': $75.0 \%$ ), although in the 'before' group reading books of specific authors scored even higher (78.3\%). Getting information about new books one can potentially read may be one of the most important functions of Shelf as was also indicated by some participants. An overview of results of communication can be found in Fig. 11.

7.5 What information would the target group want to receive from, and give to, their friends who are using the same online community?

The most important information to receive from others was in both groups recommendations ('before': $91.3 \%$, 'after': 87.5\%), followed by information about books read by the other person(s) ('before': 78.3\%, 'after': $62.5 \%$. Recommendations were also considered most important to give to others ('before': 95.7\%, 'after': $62.5 \%$ ). The lower percentages in the 'after' group can be explained by the higher percentages of participants in the 'after' group that chose the 'other' categories. An overview of important information to receive and give can be seen in Fig. 12.

The most important functionalities mentioned by the participants in the 'after' questionnaire were getting aware of new (unknown) books that are possibly interesting to read, seeing what others have read, having an overview of what you have read before and still want to read, recommendations, advice and opinions of others (who you know and whose opinions you can judge in relation to your own). 
Fig. 12 Information

respondents in the 'before' and 'after' groups indicated to want to give to friends and receive from them. Respondents were asked to indicate all information they considered important to communicate about

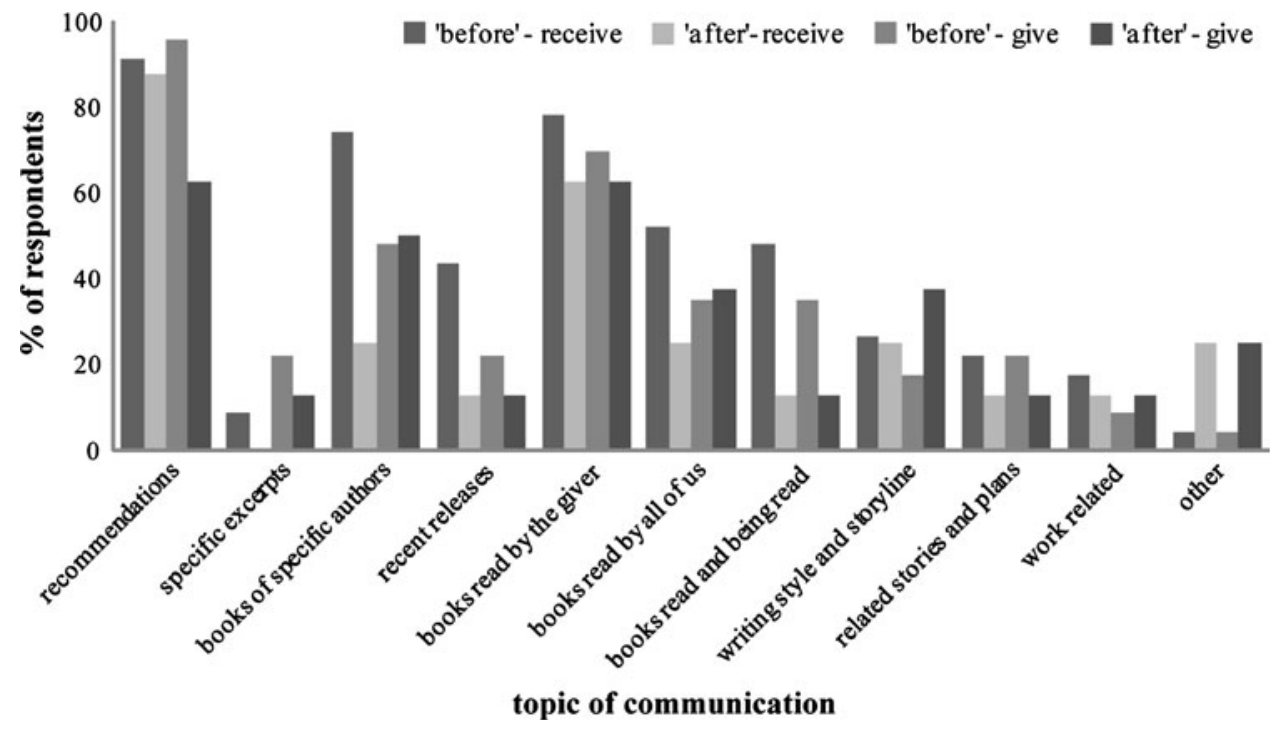

7.6 Conclusion: does a social book network, like Shelf, increase communication about books?

When drawing a conclusion from the sub-questions answered above, the main research question can be answered affirmative. The duration of the evaluation was probably a bit short to evaluate communication thoroughly, which was also confirmed by the participants in the Shelf evaluation. However, because of time-constraints, it was not possible to extend the evaluation period. Actual frequency increases may also be caused by the setup of the experiment. Nevertheless, the perceived significance of book communication and the enthusiasm of the participants about the possibilities and involvement with Shelf in our study indicate increased activeness and awareness of book communication, which appears to be valued.

\section{Discussion}

When looking at the comparison between the 1981 study by Csikszentmihalyi and Rochberg-Halton [6] and our study, it can be seen that the reasons for cherishing books have not changed much in the course of almost 30 years. Also, the easily triggered stories and comments of our interviewees revealed a deeply rooted passion for books and reading, addressing both the contents and the physical books. Despite all technological developments that have taken place in-between the two studies, such as internet and e-books, people still attach a lot of value to traditional, physical books. Our interviewees regarded recent developments, such as e-books and audio-books completely different media, rather than replacements of books. In the coming years, many more advances will be reached in the field of digital information, but drawing a conclusion from our findings our expectation is that the extent to which and the reasons why people value books will not change any time soon. The physical book is still too valuable due to the reasons presented in this paper, such as relating it to Self, Experience and Personal Values. Interestingly, in our interview, study books that were borrowed, from libraries or acquaintances, were not considered as valuable as books owned by the respondents. For some respondents, it was even the case that if they read a book and bought it later, that purchased book would not be as valuable, because they had not read that specific book. An increase in value appears to occur when a person moves from getting acquainted with the contents of a book to owning a physical copy of the book and eventually getting to know that specific book. This seems to implies that the reasons for valuing books, such as having individual experiences with it or enjoying it, move beyond the content alone. Reading a book can be enjoyable, even when it is not your book, but this feeling appears to be enhanced by owning the book, e.g., because of associations or memories with that specific physical book.

The most coded non-person reason for valuing books was Experience, which consisted of the categories: enjoyment, ongoing occasions and release. This implies books have, to a large extent, a hedonistic character, bringing the reader pleasure, support for frequent pleasant occurrences, e.g., cooking or embroidery, or a way to escape daily stress. Although this was also found to be the most important reason in Csikszentmihalyi and Rochberg-Halton's study [6], it is still, in a way, a surprising finding. In the early existence of books and reading, the main function was to store and convey knowledge, while those capable of reading were limited to the educated elite. Nowadays still, there are many books that are written to discuss and spread knowledge. Reading such books may not be a very 
pleasurable activity as such, but one can learn a great deal from it. The answer to why such books are valuable would then relate to the categories Utilitarian (e.g., expanding knowledge or gaining understanding in a certain field) or Personal Values (e.g., when a person's ideal is to learn or when (s)he is proud to have achieved something with this knowledge). Especially in the Personal Values category, we would have expected somewhat more results for this reason, as was also the case in Csikszentmihalyi and Rochberg-Halton's study [6]. Nevertheless, we did find some interesting new subcategories in the Personal Values category: 'belongs to me', 'personification', and 'personal growth'. Although these subcategories may not be found for other artifacts, they were quite important for valuing books. Another interesting finding was that there were large personal differences in reasons valuing books and each interviewee was quite consistent in his/her own reasons: an interviewee who valued one book for Personal Values was more likely to value another book also for this reason, rather than e.g., for Experience.

In our interview study, however, the special books mentioned most, by far, were novels and hobby or activity books (books meant to give people pleasure), perhaps even more so than in Csikszentmihalyi and Rochberg-Halton's study. In comparison, the most mentioned book in their study was the Bible, a book that probably relates most to the Personal Values category. This difference in mentioning religious books might have been caused by cultural differences between the Netherlands and the USA and the times the studies were executed. The high percentages of novels and hobby or activity books were probably also influenced by the education levels and occupations of the participants in the interview study, but nevertheless, with the great supply of novels meant to please a large, diverse audience that are currently on the market, the first and foremost effect people want to achieve by reading books is to have a pleasurable experience. Augmented books and other reading applications could therefore look beyond educational or 'efficient studying' functionalities and seek to address novels and other 'more pleasurable' reading purposes.

Furthermore, one of our expectations, which was confirmed by the interview study, was that books in the first place are of an individual nature, related to the most coded person category 'Self'. This means a book is valuable to a person, because it relates to individual interests or activities. In the example of one of our respondents who mentioned an insect encyclopedia, this person's whole family may not particularly like insects, but he does, so he has an individual meaningful relation with that book about insects. Furthermore, the experience a person has with a book is mostly individual: many respondents referred to quiet moments alone with a book, away from daily stress.
Nevertheless, in the interview study, concept consultations and certainly user evaluations of the Shelf Web site, participants repeatedly expressed the need and desire to share opinions about books with others, knowing what others are reading, giving and receiving recommendations, etc. This indicates there is also a strong collective nature of books, which people seek to fulfill in various ways, ranging from occasional discussions at e.g., birthday parties to regularly organized book club meetings. A social networking tool, such as the Shelf Web site can facilitate this need for collectiveness anytime, anyplace, giving people the opportunity to pass small, specific remarks as well as complete book reviews.

The user evaluation with Shelf has shown a main function of the social networking tool should be to point out books that are potentially interesting to readers. A good way to support this is using recommendations and reviews made by friends. Respondents indicated they value their friends' opinions about books, because they know them and can assess their opinions in relation to their own. Seeing what others have read and are reading contributed to the 'inspiration' aspect and also encouraged people to actively start communicating with others about books. Keeping in mind the found reasons for valuing books, augmented books and other reading applications could implement these functions to support the readers in their reading practices and needs.

When comparing the opportunities and implications of using a Web site like Shelf to those of book clubs, many differences can be seen. In book clubs the general procedure is that all participants read the same book and discuss this periodically or after they have finished reading it. This requires a certain time and reading speed alignment (synchronous), which could be troublesome for some participants. On a Web site like Shelf, on the other hand, participants are free to choose what and where they read. Participants can read different books at different times and speeds. They can comment on a book anytime and in any amount of detail (asynchronous). Other participants can read their comments whenever they feel these could be important to them, e.g., after finishing reading the book, when reading a specific excerpt, or even before reading it, as some sort of preparation.

Also the effects of online discussions compared to faceto-face discussions can differ greatly. As discussed in the Related Work section, online discussion through a Web site may help to increase equality and activeness of participation of all participants [10]. While in face-to-face book clubs there may be some persons that tend to dominate discussions, online everybody can make comments, without having to wait for their turns or without being interrupted [10]. Book clubs can, however, provide a stronger trigger and peer-pressure to keep reading, while on the other hand they 
may become an obligation or a burden, because of their little freedom and flexibility. Obviously, book clubs are also a means to get out and meet people, which is lacking in the online communication functionality.

Further communication causes and effects differ greatly when comparing online to face-to-face communication. An important factor missing in online communication is the nonverbal communication, such as eye contact, face expression and gestures, which can give additional information in a conversation and can help to verify the reliability of a comment. Furthermore, in online communication comments have to be posted, read and responded, to, which can take many iterations and time. Possibly online communication has a more one-way character, in which not all comments are responded to, although they may have been read by others. However, online communication does provide more possibilities for public as well as private communication, while in group discussions social standards may not leave room for private conversations.

Another large advantage of online book communication is that it is an automatic archive of all books, opinions, questions and reviews, while in book clubs this is often not recorded. Nowadays some book clubs have their own Web sites on which they post their books and findings, but this is not a book club's core activity. Posting results after meetings is cumbersome and the posted information represents only the interpretation of a single person. With online communication the richness of different opinions, writing styles, and (dis)agreements can be preserved.

To summarize, book communication through a Web site like Shelf is asynchronous, remote and semi-interactive, while communication through e.g., a book club is synchronous, collocated and interactive. This could imply that a Web site like Shelf addresses a different target group, for example people who are geographically removed, people who have very limited time or irregular time-schedules (e.g., due to working shifts), or people who are interested in rare, very specific book genres. Such groups of people could find each other through an online communication medium, while face-to-face communication could be troublesome. In this regard, a social network enhancement, such as Shelf, can be a valuable enhancement of books, as long as it supports the varied ways people want to deal with their books, e.g., cherish their physical books, desire to discuss with a whole group or with one specific person, very frequently or once in a while, or maybe they just want to enjoy reading a good book.

\section{Conclusions}

In this paper, we have investigated a specific type of valued physical artifacts, namely books and how these objects can be enhanced with a new product, system or service. In a qualitative interview study, the most important reasons for valuing books were found to relate to the self, experiences and personal values. These results were similar to the results of a study by Csikszentmihalyi and RochbergHalton [6], despite almost 30 years of (technological) developments. Still books appear to be important to people, both their contents and their physicality. In our interview study, the categories mentioned most as valued were novels and hobby or activity books, which indicated the first and foremost effect people want to achieve by reading books is to have a pleasurable experience. Therefore, a good opportunity for augmenting books and other reading applications could be to look beyond educational or 'efficient studying' functionalities, address novels, and support 'more pleasurable' reading purposes.

Furthermore, despite the individual nature of books, respondents expressed clearly a desire to communicate about books. Communication about books was studied through an online communication network system, called Shelf. The evaluation of this system provided insights in the way people communicate about books and the significance of book communication for people. A social network seems a valuable enhancement for books and especially awareness and recommendation functions would be a most valued addition. Such a network system should point out books that are potentially interesting to the user, by using recommendations and reviews made by friends, and notifications of what others have read and are reading. In this way, the system can provide inspiration and encourage active book communication. The evaluation further showed that book communication through a Web site like Shelf is asynchronous, remote and semi-interactive, while communication through e.g., a book club is synchronous, collocated and interactive. A Web site like Shelf could therefore address target groups that have difficulties meeting face-to-face, such as people who are geographically removed, people who have limited or irregular time to communicate, or people with specific book interests. In these cases, online book communication can support their needs and make a social network enhancement a valuable enhancement of books for various target groups. When designing such a book enhancement, the various ways people want to deal with their books should be respected and supported, e.g., that they cherish their physical books, have the desire to discuss with others, or read for enjoyment.

Acknowledgments The authors would like to thank all participants in the interview study, concept consultations and evaluation of Shelf for their valuable comments, Sven Heijthuijzen for his help with the implementation of Shelf, Guust Hilte, Pei-Chun Chen and Shirley Elprama for their feedback in team meetings, and the staff of the Industrial Design department at the Eindhoven University of Technology for their expertise. 
Open Access This article is distributed under the terms of the Creative Commons Attribution Noncommercial License which permits any noncommercial use, distribution, and reproduction in any medium, provided the original author(s) and source are credited.

\section{References}

1. Glos JW, Cassell J (1997) Rosebud: a place for interaction between memory, story, and self. In: Proceedings of the 2nd international conference on cognitive technology (CT'97), pp 88-97

2. Dyl J, Wapner S (1996) Age and gender differences in the nature, meaning, and function of cherished possessions for children and adolescents. J Exp Child Psychol 62:340-377

3. González JA (1995) Autotopographies. In: Brahm G Jr, Driscoll M (eds) Prosthetic territories: politics and hypertechnologies. Westview Press, Boulder, pp 133-150

4. van den Hoven E, Eggen B (2009) The effect of cue media on recollections. "The End of Cognition?" a Human Technology special issue 5(1):47-67

5. Petrelli D, Whittaker S, Brockmeier J (2008) 'AutoTopography: what can physical mementos tell us about digital memories? In: Proceeding of the twenty-sixth annual SIGCHI conference on human factors in computing systems, pp 52-63

6. Csikszentmihalyi M, Rochberg-Halton E (1981) The meaning of things: domestic symbols and the self. Cambridge University Press, Cambridge, UK

7. Merriam-Webster Dictionary: http://www.merriam-webster.com/ dictionary/ [accessed February 22, 2010]

8. Statistics Netherlands (2009) CBS: http://www.cbs.nl/ [accessed February 22, 2010]

9. Daniels H (2002) Literature circles: voice and choice in book clubs and reading groups, 2nd edn. Stenhouse, Portland

10. Wolsey TD (2004) Literature discussion in cyberspace: young adolescents using threaded discussion groups to talk about books. Read Online 7(4). Available: http://www.readingonline.org/ articles/art_index.asp?HREF=wolsey/index.html [accessed February 22,2010$]$

11. Sedo DR (2003) Readers in reading groups: an online survey of face-to-face and virtual book clubs. Conv Int J Res New Media Technol 9(1):66-90

12. Daniels H (2006) What's the next big thing with literature circles? Voices Middle 13(4):10-15

13. Hartley J, Turvey S (2001) Reading groups. Oxford University Press, USA

14. Long E (1986) Women, reading and cultural authority: some implications of the audience perspective in cultural studies. Am Q 38(4):591-612

15. Howie L (1998) Speaking subjects: a reading of women's book groups. Dissertation, La Trobe University

16. Davidoff S, Bloomberg C, Li IAR, Mankoff J, Fussell SR (2005) The book as user interface: lowering the entry cost to email for elders. CHI '05 extended abstracts on human factors in computing systems, pp 1331-1334

17. Back M, Cohen J, Harrison S, Minneman S (2002) Speeder reader: an experiment in the future of reading. Comput Graph 26(4):623-627

18. Hengeveld B, Hummels C, Overbeeke K, Voort R, van Balkom H (2008) Let me actuate you. In: Proceedings of the second international conference on tangible and embedded interaction (TEI'08), pp 159-166

19. Billinghurst M, Kato H, Poupyrev I (2001) The MagicBook: a transitional AR interface. Comput Graph 25(5):745-753

20. Dünser A, Hornecker E (2007) An observational study of children interacting with an augmented story book. In: Proceedings of edutainment, pp 305-315

21. Smith J III (1995) United States patent: interactive book device. Patent no. 5466158. Available: http://www.google.com/patents/ about?id=8X8cAAAAEBAJ $\&$ dq $=5466158$ [accessed February 22, 2010]

22. Back M, Cohen J, Gold R, Harrison S, Minneman S (2001) Listen reader: an electronically augmented paper-based book. In: Proceedings of the SIGCHI conference on human factors in computing systems, pp 23-29

23. Levisohn A, Cochrane J, Gromala D, Seo J (2007) The meatbook: tangible and visceral interaction. In: Proceedings of the 1st international conference on tangible and embedded interaction (TEI'07), pp 91-92

24. Chao PY, Chen GD (2006) Tangible books with context-aware supports: a mobile phone to augment reading practice with virtual learning community. In: Proceedings of the IEEE international conference on sensor networks, ubiquitous, and trustworthy computing (SUTC'06), pp 104-109

25. Klemmer SR, Graham J, Wolf GJ, Landay JA (2003) Books with voices: paper transcripts as a tangible interface to oral histories. In: Proceedings of the SIGCHI conference on human factors in computing systems, pp 89-96

26. Klemmer SR, Li J, Lin J, Landay JA (2004) Papier-Mache: toolkit support for tangible input. In: Proceedings of the SIGCHI conference on Human factors in computing systems, pp 399-406

27. Norrie MC, Signer B (2003) Web-based integration of printed and digital information. In: Efficiency and effectiveness of xml tools and techniques and data integration over the web. Springer, Berlin/Heidelberg, pp 200-219

28. Chien-Meng May D, Kristensen BB, Nowack P (2001) Tangible objects: modelling in style. Department of Computer Science, Aalborg University, Denmark. Available: http://citeseerx.ist.psu. edu/viewdoc/summary?doi=10.1.1.15.8346 [accessed February 22, 2010]

29. Marshall CC, Price MN, Golovchinsky G, Schilit BN (1999) Collaborating over portable reading appliances. Pers Ubiquit Comput 3(1-2):43-53

30. Coffey AJ, Atkinson PA (1996) Making sense of qualitative data: complementary research strategies. Sage Publications Inc, Thousand Oaks 